\title{
Seven Years of Radionuclide Laboratory at IMC - Important Achievements
}

\author{
M. HRUBÝ ${ }^{1}$, J. KUČKA ${ }^{1}$, J. PÁNEK ${ }^{1}$, P. ŠTĚPÁNEK ${ }^{1}$ \\ ${ }^{1}$ Institute of Macromolecular Chemistry of the Czech Academy of Sciences, Prague, Czech \\ Republic
}

Received July 14, 2016

Accepted July 14, 2016

\section{Summary}

For many important research topics in polymer science the use of radionuclides brings significant benefits concerning nanotechnology, polymer drug delivery systems, tissue engineering etc. This contribution describes important achievements of the radionuclide laboratory at Institute of Macromolecular Chemistry of the Academy of Sciences of the Czech Republic (IMC) in the area of polymers for biomedical applications. Particular emphasis will be given to water-soluble polymer carriers of radionuclides, thermoresponsive polymer radionuclide carriers, thermoresponsive polymers for local brachytherapy, polymer scaffolds modified with (radiolabeled) peptides and polymer copper chelators for the therapy of Wilson's disease.

\section{Key words}

Radionuclide • Radiopharmaceutical • Polymer • Drug delivery

\section{Corresponding author}

M. Hrubý, Institute of Macromolecular Chemistry of the Czech Academy of Sciences, Heyrovského nám. 2, 16206 Prague 6, Czech Republic. Fax: +420296809410. E-mail: mhruby@centrum.cz

\section{Introduction}

Institute of Macromolecular Chemistry of the Czech Academy of Sciences (IMC) is one of the leading polymer research institutions in Europe covering all major topics in this emerging field. For many of these leading research topics, beginning from nanotechnology, polymer drug delivery systems, tissue engineering, etc., the use of radionuclides brings significant benefits. The main effort of the radionuclide laboratory at IMC is devoted to the use of radionuclides in biomedicine, both in research and practical use.

There are two principal questions involving polymer biosciences and radiochemistry: 1. "What can bring the use of radionuclides to polymer biosciences?" and 2. "What can polymer science bring to radiochemistry and nuclear medicine?"

The answer to the first question lies especially in the use of suitable radionuclides to noninvasively track the fate and biodistribution of nanosized devices in organism in biological behavior studies. For instance, labeling with ${ }^{99 \mathrm{~m}} \mathrm{Tc}$ and subsequent scintigraphy became the main method of choice to follow the fate of aerosols and pulmonary drug delivery devices in lungs and airways in general (Scheuch et al. 2010). Although fluorescent labels are now generally preferred to other methods for this use, radiolabeling with $\gamma$-emitters or positron emitters with suitable properties (e.g. ${ }^{111} \mathrm{In},{ }^{99 \mathrm{~m}} \mathrm{Tc}$ or ${ }^{18} \mathrm{~F}$ ) has numerous advantages compared to any other method (Hong et al. 2009a, Ting et al. 2009, Ting et al. 2010). Gamma emitters and positron emitters can be detected by single-photon emission computed tomography (SPECT) and positron emission tomography (PET), respectively. PET imaging gives better results than SPECT with respect to quantification of biodistributions. However, software improvements have been done recently to allow good quantification of SPECT data (Cutler et al. 2013). The main advantages of radionuclide imaging techniques are:

- Radioatom has far lower size than common 
organic dye fluorophores or even quantum dots, so its influence on the physicochemical properties and biological behavior of the studied nanosystem is lower (in case when, e.g. chelator agents are not used for radiolabeling). In addition, the necessary amount of radionuclide for imaging is orders of magnitude lower than the necessary amount of the organic dye.

- Exact quantitative determination of the label concentration in the target tissue is significantly more accurate compared to fluorescence and is very easy to measure. If a radionuclide with sufficiently high $\gamma$-photon energy is used, self-absorption in tissue is negligible (unlike in the case of light used for fluorescent studies).

- Photobleaching/fluorophore photolysis does not exist for radionuclide studies (autoradiolysis is negligible in activities used for biological studies).

However, the important odds are the production of radioactive waste and relative difficulties in tracking intracellular organelle distributions with radiolabeled compounds compared to fluorescence microscopy. The often mentioned health risk of radiation is not statistically significant for the doses used for research purposes if safety precautions are fulfilled. In addition, the fact that the radioactivity is easier to measure even in extremely low (and from the health protection scope of view insignificant) amounts compared to the concentration of some highly carcinogenic organic fluorophores or heavy metals - containing quantum dots may lead to underestimation of the health risk of fluorescence studies. Detailed comparison of sensitivity, spatial resolution and other characteristics for nuclear and fluorescence techniques has been elaborated recently (Singh et al. 2016, Faust et al. 2016).

The answer to the second question ("What can polymer science bring to radiochemistry and nuclear medicine?") is more challenging. Most currently studied nanosystems designed for medicinal purposes are chemical drug or nucleic acid (gene) delivery systems. Radionuclides however have certain advantages compared to chemical drugs for the nanosized drug delivery systems (Hruby et al. 2007, Hruby et al. 2009a, Hruby et al. 2009b, Ting et al. 2009, Ting et al. 2010), in particular:

- In most cases it is not necessary to cleave the radionuclide from the carrier for imaging or therapy due to sufficient effective range of the radiation in the tissue.

- The effective amount of a radionuclide (typically in nanogram scale for common carrier-free therapeutical radionuclides for human patients) is much lower than the effective amount of any chemical drug (typically in milligram scale).

- Because internalization of the radionuclide carrier into the cell is usually not necessary, multidrug resistance, common against chemical drugs, does not apply (however, some drug delivery devices circumvent multidrug resistance by inhibiting P-glycoprotein and related ABC-transporters (Colabufo et al. 2010, Dong and Mumper 2010, Hanke et al. 2010)).

- Biodistribution may be followed during therapy to customize care for the individual patient (theranostics).

The main disadvantage of the radionuclides for medicinal use is that certain radiation burden of healthy tissues cannot be avoided, but may be minimized by rapid radionuclide deposition kinetics or in some cases by use of radiation with extremely short effective range (such as Auger electrons). For radiotherapy, one must also consider that larger tumors are usually hypoxic in the middle (Feige 2010, Matsumoto et al. 2010, Hong et al. 2009a), which decreases radiosensitivity (Moyal 2008), because the free oxygen-dependent formation of reactive oxygen species is the main mechanism of action of $\gamma$ - and partly also $\beta$-radiation. On the other hand, the main mechanism of biological effects of $\alpha$-radiation and Auger electrons is the free oxygen-independent formation of DNA double strand breaks (Hong et al. 2009b).

Polymers and supramolecular polymer assemblies such as micelles may take advantage of Enhanced Permeability and Retention (EPR) effect to accumulate in solid tumor tissue. The EPR effect is a property of most solid tumors and means that the tumor filters off and concentrates in tumor tissue large molecules or supramolecular assemblies as micelles or nanoparticles of tens of thousands to millions $\mathrm{kDa}$ mass (Maeda 2001, 2012, 2013). The accumulation principle is that the endothelium of blood vessels in normal tissue is impermeable for macromolecules, while the fast grown endothelium of neovasculature in solid tumors is generally permeable for macromolecules up to ca $200 \mathrm{~nm}$ in diameter depending on the tumor type and animal species (Torchilin 2007, Maeda et al. 2013). Additionally, solid tumors have poor or even completely missing lymphatic drainage, which further hampers elimination of macromolecules from tumor interstitial space. The EPR effect-based targeting may also be effectively combined with ligand-based targeting with ligands to receptors overexpressed on target.

While these targeting principles are well- 
established for nanocarriers of anticancer chemotherapeutics, they may therefore bring also significant benefits to polymer radiopharmaceutics for cancer applications. Despite advances in drug delivery systems in the past two decades, polymer nuclear medicine applications still remain well underestimated compared to more than 100,000 citations to date for delivery systems for chemical drugs (Figure 1). Therefore, the aim of our research was to transfer experience from polymer carriers of chemical drugs to polymer carriers of radionuclides.

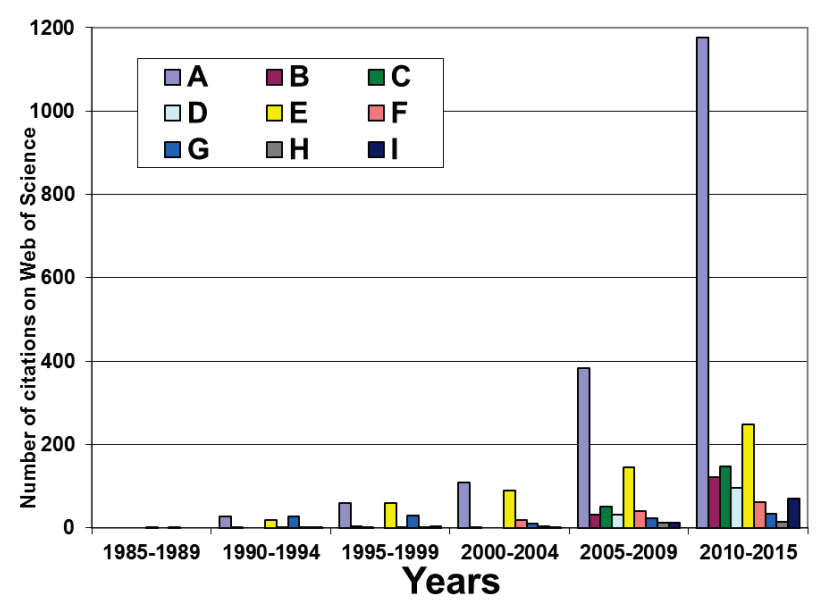

Fig. 1. Number of citations in the course of time on the main topics of application of nanoscience in nuclear medicine (according to Web of Science). A: (nanoparticles or colloid) AND (tumor OR tumour) AND (radio* OR PET OR SPECT OR scintigraphy); B: micelle* AND (tumor OR tumour) AND (radio* OR PET OR SPECT OR scintigraphy); C: quantum dot* AND (tumor OR tumour) AND (radio* OR PET OR SPECT OR scintigraphy); D: (nanotubes or nanodiamonds) AND (tumor OR tumour) AND (radio* OR PET OR SPECT OR scintigraphy); E: liposomes AND (tumor OR tumour) AND (radio* OR PET OR SPECT OR scintigraphy); F: dendrimer* AND (tumor OR tumour) AND (radio* OR PET OR SPECT OR scintigraphy); G: (reticuloendothelial OR (bone marrow AND liver AND spleen)) AND (colloid* OR nanoparticles) AND (radio* OR PET OR SPECT OR scintigraphy); $\mathrm{H}$ : (nanoparticles OR colloid) AND radiosynovectomy; I: (nanoparticles OR colloid) AND brachytherapy.

In this article, we present the most important advances reached in the radiolaboratory at the IMC.

\section{Water-soluble polymer carriers of radionuclides}

The $\mathrm{pH}$-value of blood plasma and interstitial body fluid is maintained to be exactly 7.4 (Gillies and Frechet 2005). However, there exist compartments with significantly different acidity in the organism. The endosome and lysosome content is also more acidic than blood plasma $(\mathrm{pH}$ 5.5-6.5 for early endosomes and $>5.0$ for late endosomes and lysosomes (Gillies et al. 2004, Bae et al. 2005)). Pathological phenomena connected with high metabolic activity of certain (especially of solid tumors (Fang et al. 2008, Lee et al. 2008, Wang et al. 2015, Coman et al. 2016)) tissues generally lower the local $\mathrm{pH}$, because rapidly metabolising cells deplete oxygen supply and thus make such tissue hypoxic. Under hypoxic metabolism the cells switch to anaerobic lactic acid-producing metabolism and the lactic acid formed acidifies the tissue to $\mathrm{pH}$ typically $<7$ and sometimes as low as 6.0-6.5 (Fang et al. 2008, Wang et al. 2015, Coman et al. 2016). Therefore systems that are relatively stable in bloodstream ( $\mathrm{pH} 7.4)$, but release the active cargo under mildly acidic conditions of solid tumor tissue possess significant benefits for targeted delivery to cancer tissue. We therefore decided to utilize this physiological specificity of cancer tissue for controlled release of chemical drugs and radiolabeled compounds in the target tumor tissue.

Radioactive decay (typically electron capture) of some radionuclides produces a shower of Auger electrons, which are potent ionizing radiation within their very short range in living tissue (typically tens of nanometers). Therefore these radionuclides must be placed to DNA-containing cell compartments and preferentially directly to DNA to be fully biologically effective (Ting et al. 2009, Ting et al. 2010, Imstepf et al. 2015). We used them for three stage targeting approach (first targeting: passive accumulation of the polymerbased system targeting into tumor tissue due to EPR effect; second targeting: $\mathrm{pH}$-controlled release of intercalator-bound Auger electron emitter in slightly acidic tumor tissue or endosome; third targeting: into DNA in cell nucleus and mitochondria by the intercalator) minimizing radiation burden of healthy tissues.

To optimize the latter two targeting steps, we first prepared two model systems having intercalator: either acridine-type (Sedlacek et al. 2012) or ellipticinetype (Sedlacek 2011, 2013, 2014, 2015) bound by acidcleavable bond to polymer.

We synthesized five 9-anilinoacridine-type drugs and their conjugates with biocompatible watersoluble hydrazide groups-containing poly[N-(2-hydroxypropyl)methacrylamide]-type polymer carrier (Sedlacek et al. 2012). All of the synthesized acridine derivatives retained their in vitro antiproliferative properties. The 
polymer conjugates were sufficiently stable at $\mathrm{pH} 7.4$ (model of $\mathrm{pH}$ in blood plasma) while releasing free drugs at $\mathrm{pH} 5.0$ (model of $\mathrm{pH}$ in endosomes).

We then utilized the same polymer carrier to bind the quaternary ellipticinium-type intercalators. We at first optimized the chemical surrounding of the hydrazone bond-containing spacer to find structure-drug release rate relationships (Sedlacek et al. 2013). The conjugate selected for further studies shows negligible drug release in a pH 7.4 buffer but releases over $40 \%$ of the ellipticinium drug within $24 \mathrm{~h}$ in apH 5.0 phosphate saline buffer. We then optimized the triple-targeted polymer radionuclide delivery system for the ellipticinederived intercalator, which contains radioisotope ${ }^{125} \mathrm{I}$ (giving high yields of Auger electrons) with high specific radioactivity $(63.2 \mathrm{GBq} / \mathrm{mg})$ (Sedlacek et al. 2014). The active compound is a potent intercalator and readily penetrates into cell nuclei. Its polymer conjugate is internalized into endosomes and releases the radioactive intercalator, which subsequently accumulates in the cell nuclei. In vivo experiments on mice with $4 \mathrm{~T} 1$ murine breast cancer showed a statistically significant increase in the survival of mice treated with the polymer radioconjugate.

In another area of applications, we have shown that water-soluble polymer carriers with radionuclides may be targeted into bone metastases by attachment hydroxybisphosphonate moieties onto polymer, which has high affinity to hydroxyapatite, the main mineral component of bone (Hruby et al. 2006). This is a promising system for applications in theranostics of both primary bone cancer and bone metastases.

\section{Thermoresponsive polymer radionuclide carriers}

Numerous polymers show interesting temperature dependence of solubility in aqueous milieu they are not soluble at low temperature and become soluble above certain critical temperature, or are soluble at low temperature and above certain temperature phase separation occurs (Gil and Hudson 2004). The second case (the polymer is soluble at low temperature and precipitates at higher temperature) is more commonly exploited in micellar systems proposed for drug delivery (Hruby et al. 2009a, Hruby et al. 2010, Gandhi et al. 2015). This behaviour is caused by competition of hydrogen bonding between the polymer and water and chain solvation (forcing the polymer to dissolve) and hydrophobic interactions, forcing the polymer to aggregate (Hruby et al. 2005, Hruby et al. 2007, Hruby et al. 2009b). Such partly hydrophilic-partly hydrophobic polymers are thus soluble at low temperature where solvation prevails. Above the lower critical solubility temperature (LCST), when solvation, decreasing with increasing temperature, cannot compensate hydrophobic interactions, the polymer chain is dehydrated (Annaka et al. 2007), the polymer coil collapses (coil-to-globule transition (Annaka et al. 2007)), the polymer becomes hydrophobic and then phase separation occurs within a relatively narrow temperature range. The LCST is the minimum in the dependence of phase separation temperature on concentration, so always the phase separation temperature exceeds LCST. The phase separation temperature is often represented by the „cloud point temperature" $(\mathrm{CPT})$, the temperature at which the solution becomes visibly turbid.

The important feature of polymers with LCST is that their transition temperature may be predictably adjusted to the needed value by increasing/decreasing the hydrophobicity of the polymer chain by copolymerization of suitable monomers (Gil and Hudson 2004, Hruby et al. 2007, Hruby et al. 2009b, Hruby et al. 2010, Gandhi et al. 2015). The increase of hydrophobicity increases hydrophobic interactions among the polymer chain and decreases the $\mathrm{CPT}$; on the other hand monomers more hydrophilic than the main monomer increase the CPT by the increase of chain solvation and suppression of hydrophobic interactions (Gil and Hudson 2004).

Block and graft copolymers with one thermoresponsive block and one or more hydrophilic blocks, which are readily soluble below CPT of the thermoresponsive block as molecular solutions. When the temperature is raised up above CPT of the thermoresponsive block, core-shell micelles are formed with core consisting of the phase separated thermoresponsive blocks surrounded by a corona of the hydrophilic blocks (Hruby et al. 2009a, Hruby et al. 2010, Bhatnagar and Venuganti 2015, Gandhi et al. 2015). A similar type of thermoresponsive nanoparticles can be prepared by heating of solution of thermoresponsive polymer in the presence of surfactant (Panek et al. 2012). Temperature-caused self-assembly of these micelles is diffusion driven and these micelles have, due to thermodynamic reasons, very narrow size distribution.

A very important advantage compared to other types of nanoparticles is that these are much easier to 
prepare (just heating of an aqueous solution of the polymer); no dialysis or other additional treatments are required. Another advantage is that the micelle dissolution into individual polymer chains may be controlled by the increase in polarity of the thermoresponsive block, e.g. by hydrolysis of relatively hydrophobic hydrolytically labile moieties in the thermoresponsive block into a more polar functionality (Hruby et al. 2007, Hruby et al. 2009b, Bhatnagar and Venuganti 2015, Gandhi et al. 2015). This increase in polarity increases the CPT and if the original thermoresponsive block had the CPT below body temperature and after degradation its CPT is shifted above body temperature, the micelles disintegrate.

Therefore, we prepared novel polymer micelles by self-assembling thermoresponsive poly[ $N$ isopropylacrylamide-graft- $N$-(2-hydroxypropyl)methacrylamide] copolymers with hydrolytically degradable $N$ glycosylamine groups between the polymer blocks as carriers to deliver diagnostic and therapeutical radionuclides into solid tumors (Hruby et al. 2009a).

The micelles were formed by fast heating of an aqueous solution of the copolymer to $37^{\circ} \mathrm{C}$. They had the hydrodynamic diameter $128 \mathrm{~nm}$ (obtained by dynamic light scattering) and slowly degraded during incubation in aqueous buffer $\mathrm{pH}$ 7.4. Labeling with both ${ }^{131} \mathrm{I}$ and ${ }^{90} \mathrm{Y}$ proceeded with high yields $(>85 \%)$. The nonlabeled polymers were not cytotoxic for any of the tested murine and human cell lines and showed significant tumor accumulation ( $>7$ tumor to muscle ratio after $24 \mathrm{~h}$ ) due to the EPR effect.

We have also synthesized radiolabeled ABA triblock copolymers poly[2-methyl-2-oxazoline - block(2-isopropyl-2-oxazoline - co - 2-butyl-2-oxazoline) block - 2-methyl-2-oxazoline], where the poly(2-methyl2-oxazoline) terminal blocks are hydrophilic and the central block is thermoresponsive. These polymers are molecularly dissolved in aqueous milieu below the cloud point temperature of the thermoresponsive central block and above CPT they form nanoparticles with diameter $200 \mathrm{~nm}$ (Hruby et al. 2010). An easier way to produce thermoresponsive nanoparticles than selfassembly of (multi) block or graft copolymers in aqueous milieu is to dissolve a thermoresponsive copolymer in the presence of a biologically acceptable surfactant (e.g. Pluronic F 127) and heat up the solution. Well-defined nanoparticles with thermoresponsive polymer core and hydrophilic surfactant corona are then formed (Konak and Hruby 2006, Konak et al. 2007, Panek et al. 2012).

\section{Thermoresponsive polymers for local brachytherapy}

Most currently studied drug delivery systems for radiotherapy are based on an active seeking agent, e.g. an antibody (Kumar et al. 2016), which acts at the same time as a radionuclide carrier. Sometimes, e.g. in the case of radiosynovectomy (Wong et al. 2014) or brachyradiotherapy (Frakulli et al. 2015, Thompson et al. 2016), positionning of a radionuclide carrier in welldefined and limited body volume is the method of choice. These radionuclide applications concern mainly treatment of joints damaged by inflammation or arthrosis by radiosynovectomy (Wong et al. 2014), which reduces pain and suppresses inflammation, but also intratumoral applications like brachytherapy (Frakulli et al. 2015, Thompson et al. 2016) or local adjuvant radiotherapy after surgical removal of malignant tissues.

Brachytherapy is most often carried out with closed emitters which are surgically implanted into the target site. After decay of the radionuclide the emitter is left in the application site or surgically removed. The advantage of brachytherapy is in high radiation doses to the tissue in the nearest neighbourhood while keeping the whole-body doses low, however, surgery is essential in such cases (Thompson et al. 2016). There is another approach possible. Thermoresponsive polymers allow for labeling of the carrier in a real solution at usual laboratory temperatures (e.g. $<25^{\circ} \mathrm{C}$ ). The carrier is then converted to insoluble form only after application to body of higher temperature, usually above $36{ }^{\circ} \mathrm{C}$ (Hruby et al. 2005, Hruby et al. 2009b, Kucka et al. 2010, Hruby et al. 2011, Schaal et al. 2016).

Combining radionuclides as curing agents with thermoresponsive polymers as their carriers, one can get a new promising therapeutic tool. Namely, such a polymer labeled with suitable beta emitter with the CPT closely below the body temperatures allows for depositing rather high doses directly in the application site, because the precipitation occurs almost immediately and with high efficiency. The solution of the polymer may be applied by injection, which is significantly easier than surgical implantation. Since the precipitate redissolves very slowly and (meth)acrylamide polymers usually do not cause any significant immune response (Liu et al. 2009) the radioactivity stays on the application site for sufficiently long time with respect to the radionuclide half-life. Moreover, the size of the polymer molecules can be adjusted below the renal threshold (ca 
$45 \mathrm{kDa}$ for methacrylamide polymers) (Kissel et al. 2001, Kissel et al. 2002), so that the re-dissolved polymer is rapidly excreted via urine. One of the key factors is then the stability of the radioactive labeling.

Drug delivery systems based on thermoresponsive polymers may therefore serve as suitable carriers for local radiotherapy. We have designed and synthesized a radioiodine labelable thermoresponsive polymer for such use (Hruby et al. 2005, Kucka 2010, Hruby et al. 2011). The polymer was synthesized by copolymerization of $N$-isopropylacrylamide with $N$-methacryloyl tyrosinamide, and then labeled by ${ }^{131} \mathrm{I}$. The solution of this labeled polymer in dimethylsulfoxide was applied to femoral muscle of male Balb/C mice. As expected, the labeled polymer was left on the application site (ca $90 \% 2 \mathrm{~h}$ post injection), decreasing slowly to ca $80 \%$ within 14 days. At 28 days post injection, ca $70 \%$ of the injected activity was still found on the application site, decreasing to ca $60 \%$ at 42 days.

No organ specific accumulation of the radioactivity released from the application site, including thyroid, was observed. The majority of the released radioactivity was excreted via urine and feces.

Pronounced dose-dependent tumor growth reduction was achieved by single dose of injectable intratumoral brachytherapy with ${ }^{131}$ I-labeled thermoresponsive polymer [poly( $N$-isopropyl acrylamide $)]$ in murine xenograft model (PC3 human prostate adenocarcinoma) (Hruby et al. 2011). Two doses the radionuclide were used, $2 \mathrm{MBq} /$ mouse and $25 \mathrm{MBq} /$ mouse. The higher dose caused gradual tumor volume reduction and 2 of 6 mice from this group were cured. The lower dose caused tumor growth retardation only. In both cases there were no signs of inflammation. The effects of both doses were statistically significant compared to untreated controls. Such injectable system should keep advantages of brachytherapy while making the drug administration easier and less invasive (injection instead of implantation), patient-tailored (splitting of doses into several depots) and bioerodable in the course of time.

However, there is a need to fine-tune depot degradation rate to the half-life of the radionuclide used. Therefore, an advanced version of such system was developed (Hruby et al. 2007). In this system a radionuclide complex is entrapped in a thermoresponsive polymer locally precipitated at body temperature after injection of a polymer - complex solution into the tissue where a therapeutic effect is required. The lifetime of the system is controlled by the rate of polymer hydrolysis, its dissolution and elimination from the body. The thermoresponsive polymer with the cloud temperature below body temperature is based on copolymers of $N$-isopropyl methacrylamide with a methacrylamide-type comonomer containing hydrophobic n-alkyls of three different sizes (C3, C6 and C12) bond by a hydrolytically labile hydrazone bond (Hruby et al. 2007). Hydrolysis of hydrazone bond results in a copolymer soluble at body temperature. Polymer dissolution is complete within $48 \mathrm{~h}$ at both $\mathrm{pH} 5.0$ and 7.4. The model therapeutic radionuclide, ${ }^{64} \mathrm{Cu}$, in the form of its hydrophobic chelate bis(quinolin-8-olato- $N, O)\left[{ }^{64} \mathrm{Cu}\right]$ copper, is efficiently kept hydrophobically entrapped in the phase-separated polymer until the dissolution by hydrolytic degradation is completed.

Some antiproliferative drugs show significant synergic effect with ionizing radiation. We prepared a polymer thermoresponsive system for synergic chemoradiotherapy exploiting this phenomenon. The system is based on injectable thermoresponsive polymer bearing the radionuclide and the hydrophobic moiety doxorubicin (Hruby et al. 2009b). In the system DOX serves as an antiproliferative agent with known synergic effects with ionizing radiation and the hydrophobic moiety controlling bioerosion and elimination of the system at the same time. DOX is bound to the polymer carrier by a hydrolytically labile $N$-glycosylamine bond. Hydrolysis of the $N$-glycosylamine bond thus controls the DOX release and dissolution of the system in model aqueous milieu. DOX is slowly released during incubation in aqueous milieu at $37^{\circ} \mathrm{C}$ causing complete dissolution of the bioerodable polymer within ca 2 weeks. The model radionuclide ${ }^{125} \mathrm{I}$, bound to a small amount of poly $(N$-isopropylacrylamide-co- $N$-methacryloyl tyrosinamide), was retained in the separated phase and also slowly dissolved during the incubation.

\section{Polymer scaffolds modified with (radiolabeled) peptides}

Another use of radionuclides as tools for polymer biosciences is that they represent readily measurable, extremely sensitive analytical tool to determine ultra-trace amounts of, e.g. peptide modifiers of tissue engineering scaffolds. Peptides are surface modifiers of tissue engineering scaffolds of primary importance, because they may promote selective adhesion and growth of the cells. Optimal concentrations of such 
peptides are extremely low, typically femtomolar, and therefore hard to determine after covalent attachment to the scaffold (Massia and Hubbell 1991, Proks et al. 2012). The use of radiolabeled peptide with subsequent radiometry or digital autoradiography if spatial distribution is needed is very elegant solution.

We introduced the Chloramine- $\mathrm{T}$ radioiodination reaction as one step in solid-phase peptide synthesis. The main advantage of this approach is, that the orthogonally-protected radio-labeled peptide attached to a solid support allows further incorporation of various reactive functional groups, e.g. alkyne and azide (PopGeorgievski et al. 2012) for click chemistry, thiol, maleinimide, lipoic acid for attachment on the gold surface, or (meth)acroyl group for radical polymerization. In addition, the purification step removing the unbound radioactive iodine is very efficient with the peptide bound to the solid support. After deprotection and cleavage the labeled ligand is obtained in high radiochemical yield and purity. The solid-phase approach is presented here on preparation of fibronectin-derived N-terminus-substituted GGRGDSGGGY $\left({ }^{125} \mathrm{I}\right)-\mathrm{NH}_{2}$ peptide and biomimetic modification of the various substrates for tissue engineering.

A simple, versatile, protein-repulsive, substrateindependent biomimetic surface modification is presented that is based on the creation of a poly(ethylene oxide) (PEO) brush on a polydopamine anchoring layer (Lee et al. 2007, Pop-Georgievski et al. 2011, Pop-Georgievski et al. 2012) and its capacity for selective follow-up modifications with various ligands using a copper catalyzed alkyne-azide cycloaddition reaction (Proks et al. 2012). The long-term stability of polydopaminepoly(ethylene oxide) surfaces can be positively improved through thermal annealing of the polydopamine layer before poly(ethylene oxide) grafting. The desired surface concentration of biomimetic peptide ligands can be controlled by adjusting the peptide concentration in the reaction mixture, then measuring the activity of ${ }^{125}$ I-radiolabeled peptides (Proks et al. 2012) that are immobilized on the substrates. The performance of the prepared substrates is tested in cell cultures with MEF cells and a human ECC line.

\section{Polymer copper chelators for the therapy of Wilson's disease}

Wilson's disease is a genetic disorder that leads to a high accumulation of copper in multiple organs with subsequent toxic effects especially on liver and neural system. The average prevalence of this disease in the general population is $1: 30,000$ and it is fatal unless treated. Current first line therapy is based on a decrease in the amounts of copper by an administration of lowmolecular-weight copper(II) chelators (penicillamine, triethylenetetramine or tetrathiomolybdate) (Ala et al. 2007, Merle et al. 2007), leading to a decreased absorption of copper from food with a subsequent increase in biological elimination. As an adjuvant therapy, high doses of zinc(II) salts are administered as these ions competitively block copper uptake from the gastrointestinal tract.

Suitable forms of zinc are not always available worldwide. Current therapies also suffer from serious side effects, such as myelosuppression, lupus and penicillamine-associated myasthenia as a consequence of the re-formation of a complex of essential elements after the gastrointestinal absorption of the chelating agent (Ala et al. 2007, Merle et al. 2007). Zinc therapy is typically accompanied with strong gastrointestinal adverse effects, with typical doses of zinc of up to $1,200 \mathrm{mg} / \mathrm{day}$, which is approximately one hundred-fold more than the typical daily intake of zinc (ca 8-15 mg) (Brewer et al. 1993).

The average uptake of copper from food ranges from 0.6-1.6 mg per day. Considering the omnipresence of copper in food, a copper-less diet is nearly impossible (van den Berghe and Klomp 2009). A significant amount of copper is eliminated through the alimentary tract followed by a subsequent re-uptake, representing higher amounts than the quantities obtained from food (ca 4.4-5.3 mg of copper is secreted daily) (van den Berghe and Klomp 2009).

We proposed a gentle therapy to eliminate harmful copper concentrations in patients with Wilson's disease using an oral administration of insoluble polymeric sorbents containing selective chelating groups for copper(II), which will lower copper uptake from diet and shift copper balance towards elimination (Skodova $e t$ al. 2013, Mattova et al. 2014). The sorbents contain triethylenetetramine, $\quad N, N$-di(2-pyridylmethyl)amine, 8-hydroxyquinoline or 8-hydroxyquinoline-5-sulfonic acid chelating groups bound to a methacrylate-based macroporous support. Nearly quantitative copper(II) uptake within minutes was achieved in buffers modeling the $\mathrm{pH}$ range present in the gastric environment $(\mathrm{pH} 2.0$ and 4.0). The sorbents demonstrated chelating selectivity for copper(II) against zinc(II) with ratios of up to 940 (for 8-hydroxyquinoline) (Skodova et al. 2013). The sorbents 
demonstrated sufficient stability of the copper complexes against rechelation using studies in a model environment for the small intestine (the presence of chelating amino acids, $\mathrm{pH}$ 6.8).

In preliminary copper uptake experiments we have found that especially the polymer with 8-hydroxyquinoline significantly reduced copper uptake after oral administration in Wistar rats (Mattova et al. 2014). ${ }^{64} \mathrm{Cu}$ was used as radiotracer, liver radioactivity was measured to evaluate copper uptake because liver is the main copper-storing organ in organism). Further, we have proven that the polymer with 8-hydroxyquinoline radiolabeled with ${ }^{125} \mathrm{I}$ is not absorbed from gastrointestinal tract after oral administration by determining the radioactivity in organs of rats. Nonresorbability and blocking of copper uptake was also supported with small animal imaging (PET/CT) in mice, while for $\left[{ }^{64} \mathrm{Cu}\right]-\mathrm{CuCl}_{2}$ alone there is visible accumulation of radiocopper in liver, with polymer all radiocopper remains in gastrointestinal tract. In a long-term experiment with Wistar rats fed with diet containing the polymers we have found that there were no signs of polymer toxicity and the addition of polymers to the diet led to significant reduction of the copper contents in the kidneys, brains and livers of the rats. With these experiments we have shown that polymers containing specific ligands have a potential as novel therapeutics for Wilson's disease.

For this application as well as for, e.g. separation of ${ }^{64} \mathrm{Cu}$ from target after irradiation during preparation technology it is necessary to have as ligand with the highest copper-selectivity (Paurova et al. 2015). The two novel macrocyclic ligands based on trans-substituted cyclam with $N$-methyl and $N$-(4-aminobenzyl) groups as well as with two methylphosphinic $\left(\mathrm{H}_{2} \mathrm{~L} 1\right)$ or methylphosphonic $\left(\mathrm{H}_{4} \mathrm{~L} 2\right)$ acid pendant arms were synthesized and investigated in solutions. Both ligands show a high thermodynamic selectivity for divalent copper over zinc(II) (about 7 orders of magnitude difference). Complexation is significantly faster for the phosphonate ligand $\mathrm{H}_{4} \mathrm{~L} 2$ probably due to stronger coordination ability of more basic phosphonate groups which efficiently binds the metal ion in an out-of-cage complex and, thus, accelerates its in-cage binding. Glycidyl-methacrylate copolymer beads were modified with these ligands through diazotation reaction. The separation ability of the modified polymers was tested with nonradioactive copper(II) or non-carrier-added (NCA) ${ }^{64} \mathrm{Cu}$ in the presence of a high excess of zinc(II). The experiments exhibited high selectivity for copper(II) over zinc(II) originally present in solution in 900-times molar excess.

\section{Conclusions}

The IMC as one of the leading polymer research institutions in Europe covers all major topics in this emerging field. For many of these research topics that include nanotechnology, polymer drug delivery systems, tissue engineering etc., the use of radionuclides brings significant benefits. Therefore, we established radionuclide laboratory at the IMC. The main effort is devoted to the use of radionuclides in biomedicine, both in research and practical applications. Here we have highlighted the most important topics studied in the past seven years in the radionuclide laboratory at the IMC.

\section{Conflict of Interest}

There is no conflict of interest.

\section{Acknowledgements}

The work was supported by the Ministry of Education, Youth and Sports of CR within the National Sustainability Program I (NPU I), Project POLYMAT LO1507.

\section{References}

ALA A, WALKER AP, ASHKAN K, DOOLEY JS, SCHILSKY ML: Wilson's disease. Lancet 369: 397-408, 2007.

ANNAKA M, YAHIRO C, NAGASE K, KIKUCHI A, OKANO T: Real-time observation of coil-to-globule transition in thermosensitive poly (N-isopropylacrylamide) brushes by quartz crystal microbalance. Polymer 48: 5713$5720,2007$.

BAE Y, NISHIYAMA N, FUKUSHIMA S, KOYAMA H, YASUHIRO M, KATAOKA K: Preparation and biological characterization of polymeric micelle drug carriers with intracellular $\mathrm{pH}$-triggered drug release property: Tumor permeability, controlled subcellular drug distribution, and enhanced in vivo antitumor efficacy. Bioconjugate Chem 16: 122-130, 2005. 
BHATNAGAR S, VENUGANTI VVK: Cancer targeting: responsive polymers for stimuli-sensitive drug delivery. J Nanosci Nanotechnol 15: 1925-1945, 2015.

BREWER GJ, YUZBASIYANGURKAN V, JOHNSON V, DICK RD, WANG YX: Treatment of Wilsons-disease with zinc-XII - dose regimen requirements. Am J Med Sci 305: 199-202, 1993.

COLABUFO NA, BERARDI F, PERRONE MG, CAPPARELli E, CANTORE M, INGLESE C, PERRONE R: Substrates, inhibitors and activators of P-glycoprotein: Candidates for radiolabeling and imaging perspectives. Curr Top Med Chem 10: 1703-1714, 2010.

COMAN D, HUANG Y, RAO JU, DE FEYTER HM, ROTHMAN DL, JUCHEM C, HYDER F: Imaging the intratumoral-peritumoral extracellular pH gradient of gliomas. NMR Biomed 29: 309-319, 2016.

CUTLER CS, HENNKENS HM, SISAY N, HUCLIER-MARKAI S, JURISSON SS: Radiometals for combined imaging and therapy. Chem Rev 113: 858-883, 2013.

DONG XW, MUMPER R: Nanomedicinal strategies to treat multidrug-resistant tumors: current progress. Nanomedicine 5: 597-615, 2010.

FANG JS, GILLIES RD, GATENBY RA: Adaptation to hypoxia and acidosis in carcinogenesis and tumor progression. Semin Cancer Biol 18: 330-337, 2008.

FAUST A, HERMANN S, SCHÄFERS M, HÖLTKE C: Optical imaging probes and their potential contribution to radiotracer development. Nuklearmedizin 55: 51-62, 2016.

FEIGE JJ: Tumor angiogenesis: recent progress and remaining challenges. Bull Cancer 97: 1305-1310, 2010.

FRAKULLI R, GALUPPI A, CAMMELLI S, MACCHIA G, CIMA S, GAMBACORTA MA, CAFARO I, TOGLIAFERRI L, PERRUCCI E, BUWENGE M, FREZZA G, VALENTINI V, MORGANTI AG: Brachytherapy in non melanoma skin cancer of eyelid: a systematic review. J Contemp Brachytherapy 7: $497-$ 502, 2015.

GANDHI A, PAUL A, SEN SO, SEN KK: Studies on thermoresponsive polymers: Phase behaviour, drug delivery and biomedical applications. Asian J Pharm Sci 10: 99-107, 2015.

GIL ES, HUDSON SA: Stimuli-reponsive polymers and their bioconjugates. Prog Polym Sci 29: 1173-1222, 2004.

GILLIES ER, FRECHET JMJ: pH-responsive copolymer assemblies for controlled release of doxorubicin. Bioconjugate Chem 16: 361-368, 2005.

GILLIES ER, GOODWIN AP, FRECHET JMJ: Acetals as pH-sensitive linkages for drug delivery. Bioconjugate Chem 15: 1254-1263, 2004.

HANKE U, MAY K, ROZEHNAL V, NAGEL S, SIEGMUND W, WEITSCHIES W: Commonly used nonionic surfactants interact differently with the human efflux transporters ABCB1 (p-glycoprotein) and ABCC2 (MRP2). Eur J Pharm Biopharm 76: 260-268, 2010.

HONG H, GAO T, CAI WB: Molecular imaging with single-walled carbon nanotubes. Nano Today 4: 252-261, 2009a.

HONG H, ZHANG Y, SUN JT, CAI WB: Molecular imaging and therapy of cancer with radiolabeled nanoparticles. Nano Today 4: 399-413, 2009b.

HRUBY M, ETRYCH T, KUCKA J, FORSTEROVA M, ULBRICH K: Hydroxybisphosphonate-containing polymeric drug-delivery systems designed for targeting into bone tissue. J Appl Polym Sci 101: 3192-3201, 2006.

HRUBY M, FILIPPOV SK, PANEK J, NOVAKOVA M, MACKOVA H, KUCKA J, VETVICKA D, ULBRICH K: Polyoxazoline thermoresponsive micelles as radionuclide delivery systems. Macromol Biosci 10: 916-924, 2010.

HRUBY M, KONAK C, KUCKA J, VETRIK M, FILIPPOV SK, VETVICKA D, MACKOVA H, KARLSSON G, EDWARDS K, RIHOVA B, ULBRICH K: Thermoresponsive, hydrolytically degradable polymer micelles intended for radionuclide delivery. Macromol Biosci 9: 1016-1027, 2009a.

HRUBY M, KUCKA J, LEBEDA O, MACKOVA H, BABIC M, KONAK C, STUDENOVSKY M, SIKORA A, KOZEMPEL J, ULBRICH K: New bioerodable thermoresponsive polymers for possible radiotherapeutic applications. J Control Release 119: 25-33, 2007.

HRUBY M, KUCKA J, MACKOVA H, KONAK C, VETRIK M, KOZEMPEL J, LEBEDA O: new binary thermoresponsive polymeric system for local chemoradiotherapy. J Appl Polym Sci 111: 2220-2228, $2009 \mathrm{~b}$.

HRUBY M, POUCKOVA P, ZADINOVA M, KUCKA J, LEBEDA O: Thermoresponsive polymeric radionuclide delivery system-An injectable brachytherapy. Eur J Pharm Sci 42: 484-488, 2011. 
HRUBY M, SUBR V, KUCKA J, KOZEMPEL J, LEBEDA O, SIKORA A: Thermoresponsive polymers as promising new materials for local radiotherapy. Appl Radiat Isot 63: 423-431, 2005.

IMSTEPF S, PIERROZ V, RAPOSINHO P, BAUWENS M, FELBER M, FOX T, SHAPIRO AB, FREUDENBERG R, FERNANDES C, GAMA S, GASSER G, MOTTHAGY F, SANTOS IR, ALBERTO R: Nuclear targeting with an auger electron emitter potentiates the action of a widely used antineoplastic drug. Bioconjugate Chem 26: 2397-2407, 2015.

KISSEL M, PESCHKE P, SUBR V, ULBRICH K, SCHUHMACHER J, DEBUS J, FRIEDRICH E: Synthetic macromolecular drug carriers: Biodistribution of poly (N-2-hydroxypropyl)methacrylamide copolymers and their accumulation in solid rat tumors. PDA J Pharm Sci Technol 55: 191-201, 2001.

KISSEL M, PESCHKE P, SUBR V, ULBRICH K, STRUNZ AM, KUHNLEIN R, DEBUS J, FRIEDRICH E: Detection and cellular localisation of the synthetic soluble macromolecular drug carrier pHPMA. Eur J Nucl Med Mol Imaging 29: 1055-1062, 2002.

KONAK C, HRUBY M: Thermoresponsive polymeric nanoemulsions. Macromol Rapid Commun 27: 877-881, 2006.

KONAK C, PANEK J, HRUBY M: Thermoresponsive polymeric nanoparticles stabilized by surfactants. Coll Polym Sci 285: 1433-1439, 2007.

KUCKA J, HRUBY M, LEBEDA O: Biodistribution of a radiolabelled thermoresponsive polymer in mice. Appl Radiat Isot 68: 1073-1078, 2010.

KUMAR C, SHETAKE N, DESAI S, KUMAR A, SAMUEL G, PANDEY BN: Relevance of radiobiological concepts in radionuclide therapy of cancer. Int J Radiat Biol 92: 173-186, 2016.

LEE ES, GAO ZG, BAE YH: Recent progress in tumor pH targeting nanotechnology. $J$ Control Release 132: 164-170, 2008.

LEE H, DELlATORE SM, MILLER WM, MESSERSMITH PB: Mussel-inspired surface chemistry for multifunctional coatings. Science 318: 426-430, 2007.

LIU RX, FRAYLICH M, SAUNDERS BR: Thermoresponsive copolymers: from fundamental studies to applications. Coll Polym Sci 287: 627-643, 2009.

MAEDA H: SMANCS and polymer-conjugated macromolecular drugs: advantages in cancer chemotherapy. Adv Drug Delivery Rev 46: 169-185, 2001.

MAEDA H: Macromolecular therapeutics in cancer treatment: The EPR effect and beyond. J Control Release 164: 138$144,2012$.

MAEDA H, NAKAMURA H, FANG J: The EPR effect for macromolecular drug delivery to solid tumors: Improvement of tumor uptake, lowering of systemic toxicity, and distinct tumor imaging in vivo. Adv Drug Delivery Rev 65: 71-79, 2013.

MASSIA SP, HUBBELL JA: Human endothelial cell interactions with surface-coupled adhesion peptides on a nonadhesive glass substrate and two polymeric biomaterials. J Biomed Mater Res 25: 223-242, 1991.

MATSUMOTO S, YASUI H, MITCHELL JB, KRISHNA MC: Imaging cycling tumor hypoxia. Cancer Res 70: 10019-10023, 2010.

MATTOVA J, POUCKOVA P, KUCKA J, SKODOVA M, VETRIK M, STEPANEK P, URBANEK P, PETRIK M, NOVY Z, HRUBY M: Chelating polymeric beads as potential therapeutics for Wilson's disease. Eur J Pharm Sci 62: 1-7, 2014.

MERLE U, SCHAEFER M, FERENCI P, STREMMEL W: Clinical presentation, diagnosis and long-term outcome of Wilson's disease: a cohort study. Gut 56: 115-120, 2007.

MOYAL ECJ: Optimizing antiangiogenic strategies: combining with radiotherapy. Targeted Oncol 3: 51-56, 2008.

PANEK J, FILIPPOV SK, HRUBY M, RABYK M, BOGOMOLOVA A, KUCKA J, STEPANEK P: Thermoresponsive nanoparticles based on poly(2-alkyl-2-oxazolines) and Pluronic F127. Macromol Rapid Commun 33: 1683-1689, 2012.

PAUROVA M, HAVLICKOVA J, POSPISILOVA A, VETRIK M, CISAROVA I, STEPHAN H, PIETZSCH HJ, HRUBY M, HERMANN P, KOTEK J: Bifunctional cyclam-based ligands with phosphorus acid pendant moieties for radiocopper separation: thermodynamic and kinetic studies. Chem Eur J 21: 4671-4687, 2015. 
POP-GEORGIEVSKI O, POPELKA S, HOUSKA M, CHVOSTOVA D, PROKS V, RYPACEK F: Poly(ethylene oxide) layers grafted to dopamine-melanin anchoring layer: stability and resistance to protein adsorption. Biomacromolecules 12: 3232-3242, 2011.

POP-GEORGIEVSKI O, VERREAULT D, DIESNER MO, PROKS V, HEISSLER S, RYPACEK F, KOELSCH P: Nonfouling poly(ethylene oxide) layers end-tethered to polydopamine. Langmuir 28: 14273-14283, 2012.

PROKS V, JAROS J, POP-GEORGIEVSKI O, KUCKA J, POPELKA S, DVORAK P, HAMPL A, RYPACEK F: "Click \& Seed" approach to the biomimetic modification of material surfaces. Macromol Biosci 12: 12321242, 2012.

SCHAAL JL, LI XH, MASTRIA E, BHATTACHARYYA J, ZALUTSKY MR, CHILKOTI A, LIU WG: Injectable polypeptide micelles that form radiation crosslinked hydrogels in situ for intratumoral radiotherapy. $J$ Control Release 228: 58-66, 2016.

SCHEUCH G, BENNETT W, BORGSTROM L, CLARK A, DALBY R, DOLOVICH M, FLEMING J, GEHR P, GONDA I, O'CALLAGHAN C, TAYLOR G, NEWMAN S: Deposition, imaging, and clearance: What remains to be done? J Aerosol Med Pulm Drug Deliv 23 (Suppl 2): S39-S57, 2010.

SEDLACEK O, HRUBY M, STUDENOVSKY M, KUCKA J, VETVICKA D, KOVAR L, RIHOVA B, ULBRICH K: Ellipticine-aimed polymer-conjugated auger electron emitter: Multistage organelle targeting approach. Bioconjugate Chem 22: 1194-1201, 2011.

SEDLACEK O, HRUBY M, STUDENOVSKY M, VETVICKA D, SVOBODA J, KANKOVA D, KOVAR J, ULBRICH K: Polymer conjugates of acridine-type anticancer drugs with pH-controlled activation. Bioorg Med Chem 20: 4056-4063, 2012.

SEDLACEK O, KUCKA J, HRUBY M: Optimized protocol for the radioiodination of hydrazone-type polymer drug delivery systems. Appl Radiat Isot 95: 129-134, 2015.

SEDLACEK O, KUCKA J, MATTOVA J, PARIZEK M, STUDENOVSKY M, ZADINOVA M, POUCKOVA P, HRUBY M: Multistage-targeted pH-responsive polymer conjugate of Auger electron emitter: Optimized design and in vivo activity. Eur J Pharm Sci 63: 216-225, 2014.

SEDLACEK O, STUDENOVSKY M, VETVICKA D, ULBRICH K, HRUBY M: Fine tuning of the pH-dependent drug release rate from polyHPMA-ellipticinium conjugates. Bioorg Med Chem 21: 5669-5672, 2013.

SINGH G, GOTT MD, PIETZSCH H-J, STEPHAN H: Nuclear and optical dual-labelled imaging agents. Nuklearmedizin 55: 41-50, 2016.

SKODOVA M, KUCKA J, VETRIK M, SKOPAL J, WALTEROVA Z, SEDLACEK O, STEPANEK P, MATTOVA J, POUCKOVA P, URBANEK P, HRUBY M: Chelating polymeric particles intended for the therapy of Wilson's disease. React Funct Polym 73: 1426-1431, 2013.

THOMPSON SR, DELANEY GP, JACOB S, SHAFIQ J, WONG KR, HANNA TP, GABRIEL GS, BARTON MB: Estimation of the optimal utilisation rates of radical prostatectomy, external beam radiotherapy and brachytherapy in the treatment of prostate cancer by a review of clinical practice guidelines. Radiother Oncol 118: 118-121, 2016.

TING G, CHANG CH, WANG HE: Cancer Nanotargeted radiopharmaceuticals for tumor imaging and therapy. Anticancer Res 29: 4107-4118, 2009.

TING G, CHANG CH, WANG HE, LEE TW: Nanotargeted radionuclides for cancer nuclear imaging and internal radiotherapy. J Biomed Biotechnol \# 953537, 2010.

TORCHILIN VP: Micellar nanocarriers: Pharmaceutical perspectives. Pharm Res 24: 1-16, 2007.

VAN DEN BERGHE PVE, KLOMP LWJ: New developments in the regulation of intestinal copper absorption. Nutr Rev 67: 658-672, 2009.

WANG L, FAN Z, ZHANG J, CHANGYI Y, HUANG C, GU Y, XU Z, TANG Z, LU W, WEI X, LI C: Evaluating tumor metastatic potential by imaging intratumoral acidosis via $\mathrm{pH}$-activatable near-infrared fluorescent probe. Int J Cancer 136: E107-E116, 2015.

WONG Y, CHERK MH, POWELL A, CICUTTINI F, BAILEY M, KALFF V: Efficacy of yttrium-90 synovectomy across a spectrum of arthropathies in an era of improved disease modifying drugs and treatment protocols. Int $J$ Rheum Dis 17: 78-83, 2014. 